\title{
EFFECT OF METAKAOLIN ON STRENGTH AND DURABILITY OF CONCRETE
}

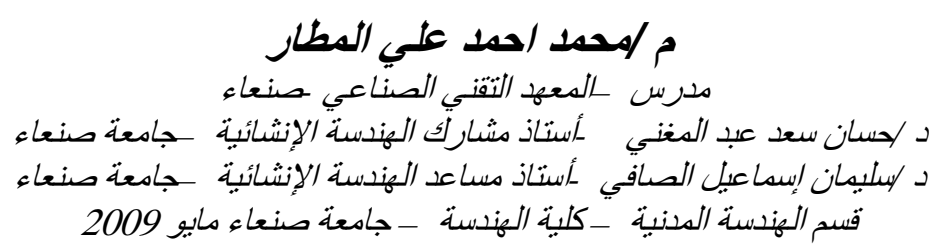

(Received September 27, 2009 Accepted October 24, 2009).

The aim of this investigation is to study the performance of concrete containing different percentages of local metakaolin and to identify the optimum addition percentage and to compare the performance of metakaolin with other pozzolanic materials as silica fume. The study focuses on the strength and durability of concrete of the blended concrete containing different percentages of metakaolin for two types.

The concrete mixture with the percentages of 5\%, 10\%, and $15 \%$ by weight of cement in the first type used $W / C=0.55$. Concrete Cubes are tested at the age of 3, 7, 14, 28, and 60 days. The results showed that the strength development of concrete blended with Metakaolin is enhanced. It was found that 5\% of Metakaolin appears to be the optimum, where concrete exhibits enhanced compressive and tensile strength at all ages compared to reference samples.

The second Type concrete mixture used superplasticizer to reduce water/cement ratio $(W / C=0.4)$ to keep the same slump $(75-120 \mathrm{~mm})$. The concrete mixture with the percentages of $5 \%$ and $10 \%$ by weight of cement is prepared. Concrete sample are tested at the age of 7, 14, 28, 60, and 90 days. In addition to both absorption and permeability test at 28 days.

The result showed that the strength development of concrete blended with metakaolin is enhanced. Also, it was found that 5\% appears to be the optimum. Where metakaolin concrete 5\% exhibits enhanced compressive and tensile strength at all ages compared to reference samples. When compared the results of silica fume and metakaolin appear to be an effective pozzolan in enhancing concrete strength. From the study, it is clear that metakaolin is a very reactive pozzolan and results in enhanced strength and some improvement in Durability.

KEYWORDS: Metakaolin; Silica fume; Compressive strength; Tensile strength; Durability; Superplasticizer; Pozzolan; Calcining Clay; Concrete, 


\section{تأثير الطين المحروق ( Metakaolin ) على مقاومة و متانة الخرسانة}

\section{الخلاصة}

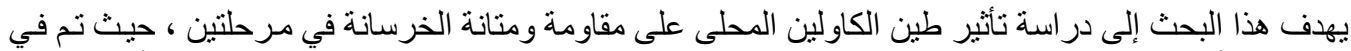
المرحلة الأولى إضافة نسب مختلفة (

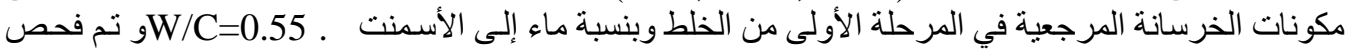

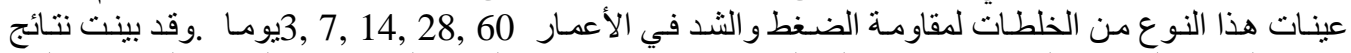

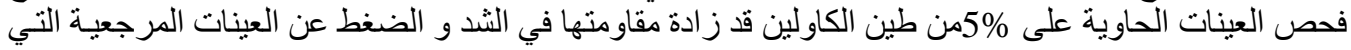

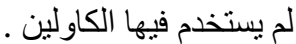

وتم في المرحلة الثانية إضافة نسبة 10\% 10\%من طين الكاولين إلى مكونـات الخرسـانة مـع استخدام مضـاف الملدن المتفوق (Superplasticizer ) لتقليل نسبة المـاء إلى الأسمنت

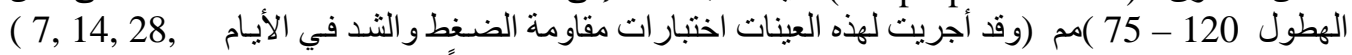
60,90, 90

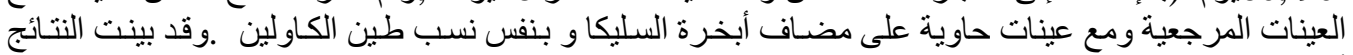

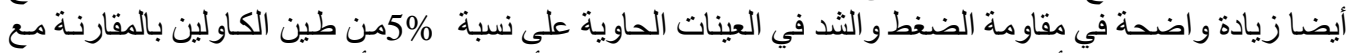

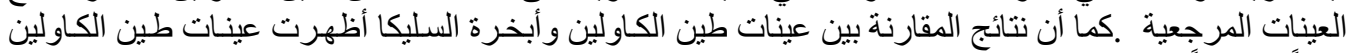

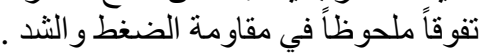

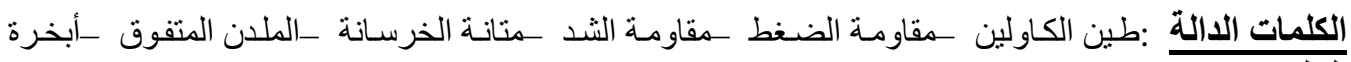
السليكا.

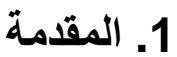

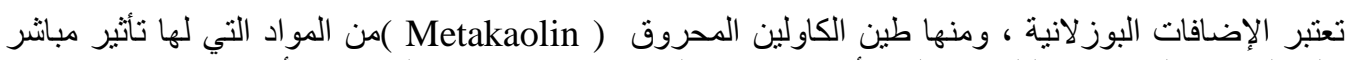

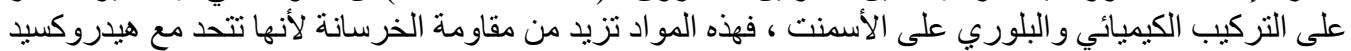

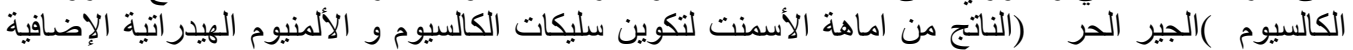

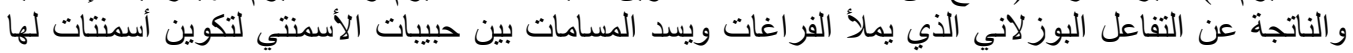

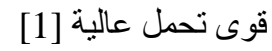

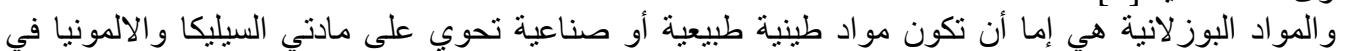

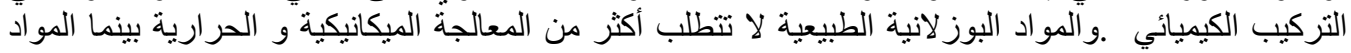

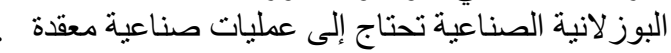

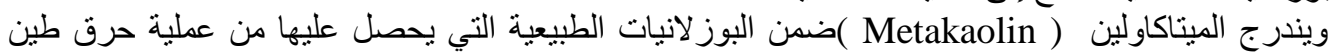

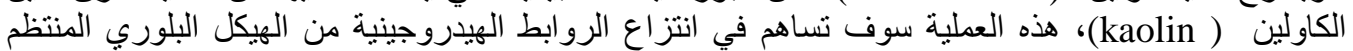

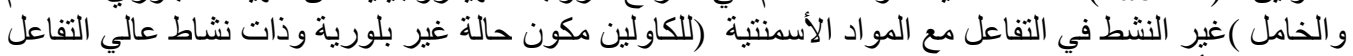
مع المو اد الأسمنتية .وتتحول إلى الحالة غير البلورية عندما تصل درجة حر ارة الاحتر اق بين ه

$$
\text { و تأثنير البوز لانيات على الخرسانة يندرج في خاصيتين هما : }
$$

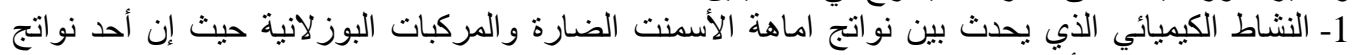

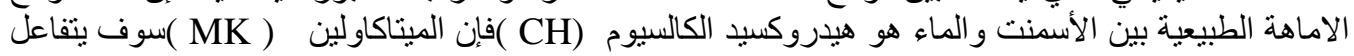

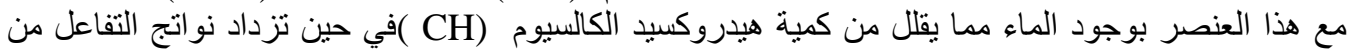

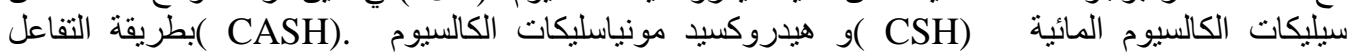

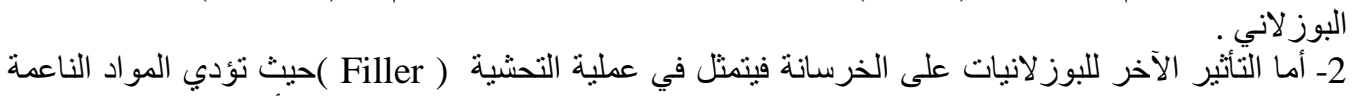

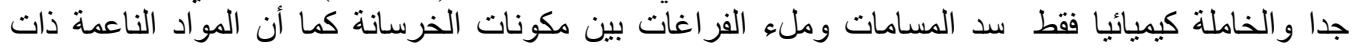

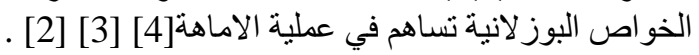

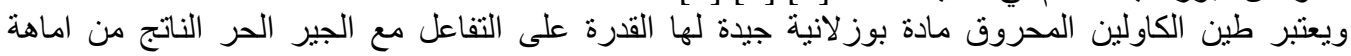

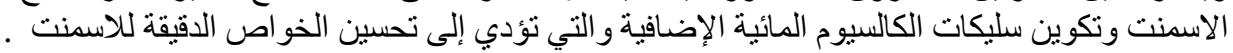


2. الأعمال المخبرية

1-2 - 2 المواد المستخدمة :

المواد المستخدمة في هذا البحث هي طين الكاولين و الأسمنت البورتلاندي العادي و الركام و أبخرة السليكا

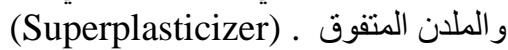
2-2 تحضير الميتاكاولين :

تم تفتيت وطحن كتل عينات الطين مبدئياً إلى درجة نعومة وصلت النسبة المارة من الدنذل 6.60مم إلى 100\%

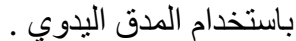

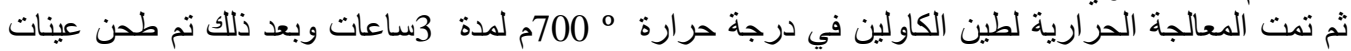

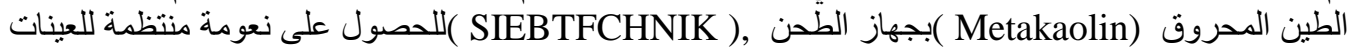
وبحيث تصل درجة النعومة في العينات إلى أنعم من الأسمنت .ونتائج فحص التحليل المنظلي لعينة الميتاكاولين

مبينة في الجدول ( 1 ) و الثكل . (1 1 (

الجدول ( 1 ) التحليل المنخلي لطين الكاولين المحروق

\begin{tabular}{|c|c|c|}
\hline $\begin{array}{l}\text { المارة بالوزن المئوية\% } \\
\text { \% }\end{array}$ & الكمية منذل (جمزة على & رقم المنذل \\
\hline 99.35 & 1.3 & 0.600 \\
\hline 88.13 & 22.4 & 0.300 \\
\hline 51.85 & 72.4 & 0.212 \\
\hline 35.57 & 32.5 & 0.150 \\
\hline 8.52 & 54 & 0.075 \\
\hline 0 & 17 & الكفة \\
\hline
\end{tabular}

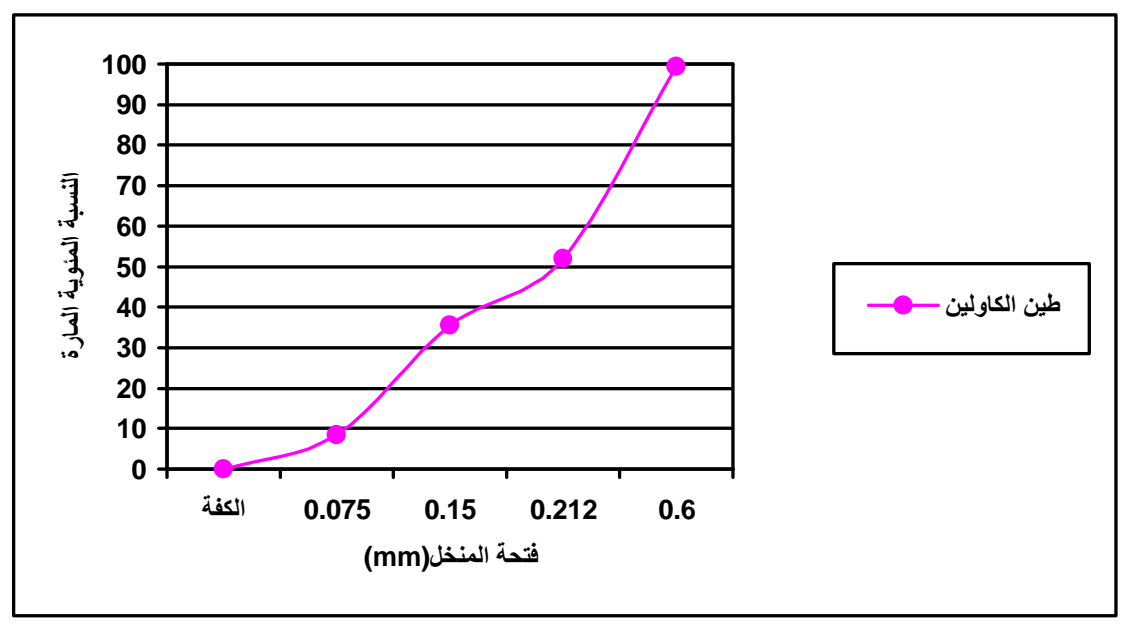

شكل ( 1 ) منحنى تدرج طين الكاولين 
تم تحضير خلطات مختلفة من المواد الأولية المستخدمة على مرحلتين والجداول 2و 3يوضحان تركيب هذه

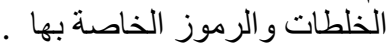

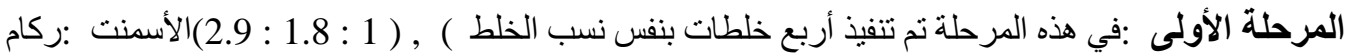

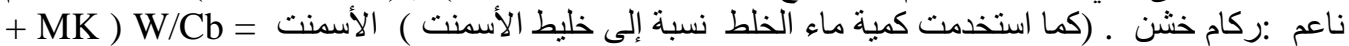

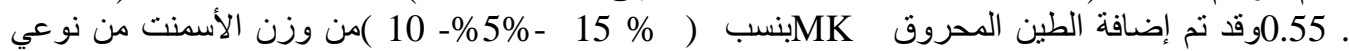

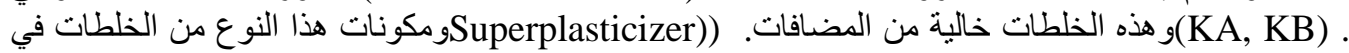
المتر المكعب موضحة في الجدول (2 2 )

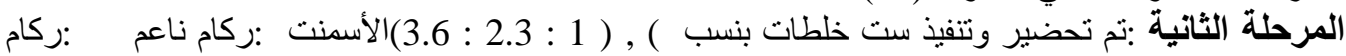

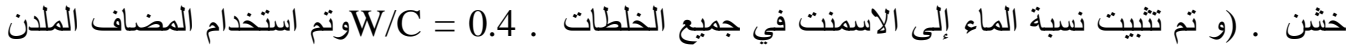

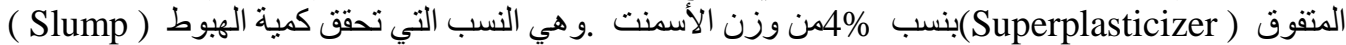
المطلوب الذي يتر اوح مابين 120 - 75 )مم (للخلطات المختلفة في هذه المرحلة .ومكونات هذه الخلطات

موضحة في الجدول (3) مالبر

جدول ( 2 ) مكونات الخلطات الخرسانية بدون Superplasticizer

\begin{tabular}{|c|c|c|c|c|c|c|c|c|}
\hline \multirow{2}{*}{$\begin{array}{c}\text { الكثافة } \\
\left(\mathrm{kg} / \mathrm{m}^{3}\right)\end{array}$} & \multicolumn{6}{|c|}{ مكونات الخليط في المتر المكعب ( Kg/m³ ) } & \multirow{2}{*}{$(\mathrm{W} / \mathrm{C})$} & \multirow{2}{*}{ الخلطة } \\
\hline & MKB & MKA & الماء & الخشن & الركام & الاسمنت & & \\
\hline 2500 & 0 & 0 & 220 & 1160 & 720 & 400 & 0.55 & $\mathrm{Rf}$ \\
\hline 2592 & 0 & 60 & 252 & 1160 & 720 & 400 & 0.55 & MK15 \\
\hline 2562 & 0 & 40 & 242 & 1160 & 720 & 400 & 0.55 & MK10 \\
\hline 2531 & 20 & 0 & 231 & 1160 & 720 & 400 & 0.55 & MK5 \\
\hline
\end{tabular}

جدول ( 3 ) مكونات الخلطات الخرسانية مع Superplasticizer

\begin{tabular}{|c|c|c|c|c|c|c|c|c|c|c|}
\hline \multirow{2}{*}{$\begin{array}{c}\text { الكثافة } \\
\left(\mathrm{kg} / \mathrm{m}^{3}\right)\end{array}$} & \multicolumn{8}{|c|}{ مكونات الخليط في المتر المكعب ( Kg/m³ ) } & \multirow{2}{*}{$(\mathrm{W} / \mathrm{C})$} & \multirow{2}{*}{ نزلطة } \\
\hline & S.F & $\mathrm{MKB}$ & MKA & SP1 & 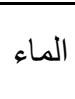 & الخثن الركام & الناعم & 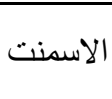 & & \\
\hline 2455 & 0 & 0 & 0 & 13.2 & 132 & 1200 & 780 & 330 & 0.4 & M1 \\
\hline 2472 & 0 & 16.5 & 0 & 13.2 & 132 & 1200 & 780 & 330 & 0.4 & M2 \\
\hline 2473 & 16.5 & 0 & 0 & 14.9 & 132 & 1200 & 780 & 330 & 0.4 & M3 \\
\hline 2492 & 16.5 & 16.5 & 0 & 16.5 & 132 & 1200 & 780 & 330 & 0.4 & M4 \\
\hline 2490 & 0 & 33 & 0 & 14.9 & 132 & 1200 & 780 & 330 & 0.4 & M5 \\
\hline 2462 & 33 & 0 & 0 & 16.5 & 132 & 1200 & 780 & 330 & 0.4 & M6 \\
\hline
\end{tabular}


( Lab. Tests ): 4-2 الاختبارات المعملية

(Slump Tests ) : 1.4 .2

استعمل فحص الهطول حسب الموصفات الأمريكية لقياس قابلية التشغيل لجميع أنواع الخلطات المنفذة في هذه الدر اسة .

\section{2-4-2/ختبارات الضغط Compression Tests )}

تم فحص مقاومة الضغط بواسطة ماكينة الاختبار SCHENCK ذات قدرة 2500كيلو نيوتن وبمعدل سرعة تحميل , (0.20 Mpa/sec ) وهي ضمن القيمة المحددة لفحص المو اد التي حددتها مو اصفات المؤسئة الأمريكية لاختبار المواد ( MSTM C 39M ) بين . Mpa/sec (0.35 - 0.15 ) 0.15 ) وتمثل نتيجة المعدل الحسابي لثناثة نماذج التبن عند كل عمر روقد أجريت اختبار ات مقاومة الضغط لعينات النوع الأول

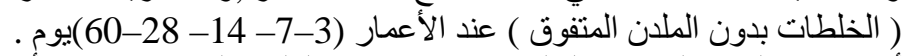

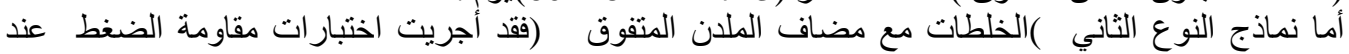

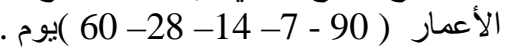

3-4-2

تم فحص نماذج مقاومة الثد الاسطوانية بطريقة اختبار الثد بالفلق

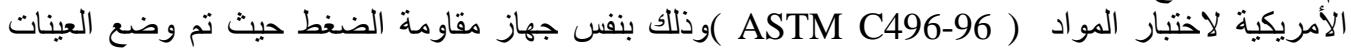

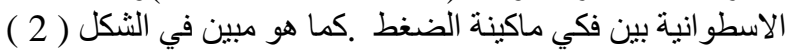

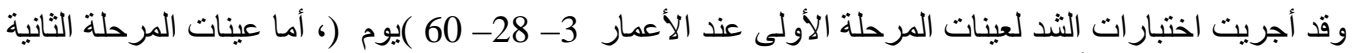

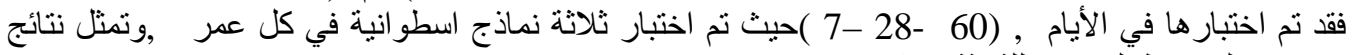
الاختبار المتوسط آلحسابي للثناثة نماذج الخاذ

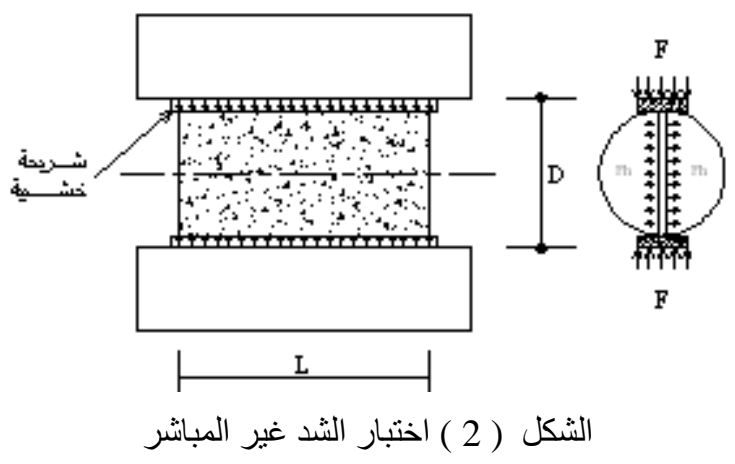

(Absorption Test (ختبار الامتصاصِ(-4-2

تم فحص الامتصاص بحسب مواصفات الجمعية الأمريكية لاختبار المواد (ASTM C 642-97) لثلاثة

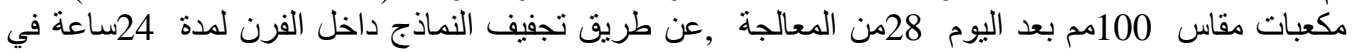

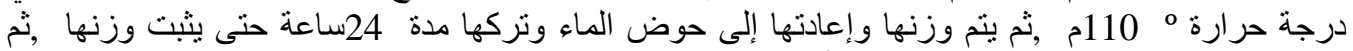
يحسب مقدار الامتصاص طبقا ه للمعادلات الآتية:

Absorption $\%=((\mathrm{B}-\mathrm{A}) / \mathrm{A}) * 100$

$$
\begin{aligned}
& \text { :وزن العينة مشبعة بالماء. B } \\
& \text { Aوزن العينة جافة. }
\end{aligned}
$$




\section{5ermeability Test ) 5-4-2 اختبار النفاذية}

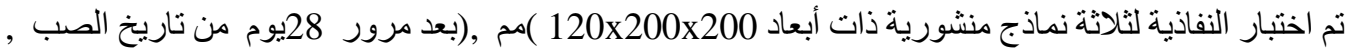

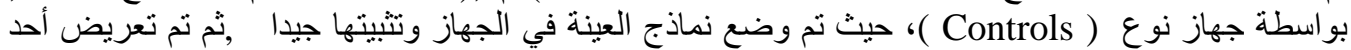
أوجهها لضغط الماء المسلط من جهاز الضغط الهيدروليكي بمقدار (

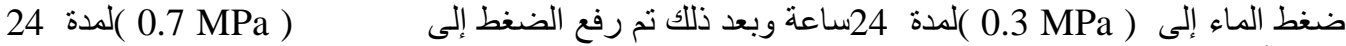

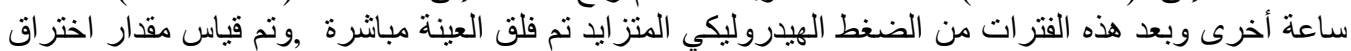

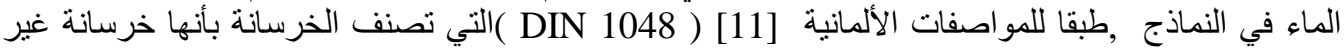

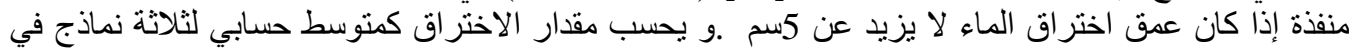
العينة الواحدة.

\section{3-النتائج والمناقشة :}

\section{(Compression Strength ) 1-3 مقاومة الضغط} 1-3-3 الخرساتة بلدون استخدام المضاف الملان( W/C=0.55 ) . جميـع نتائج اختبـار ات الضـغط للخرسـانة بإضـافة نسـب مختلفـة مـن الطبن المحروق إلى مكونـات الخرسـانة

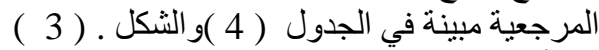

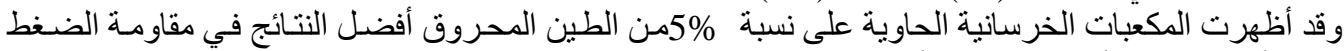

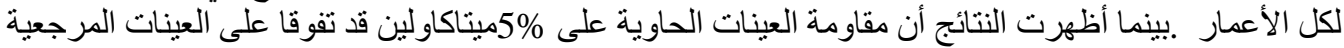

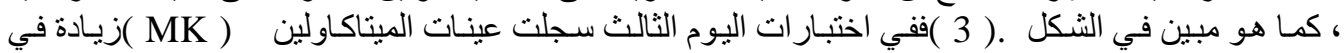

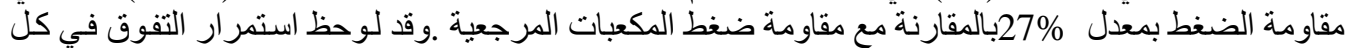
الأعمار إلا أن معدل الزيادة قد اختلف إلى \%

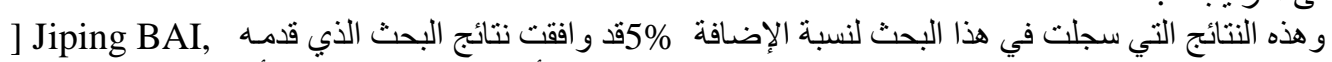

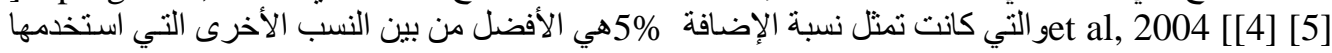

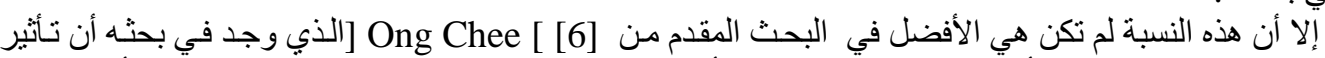

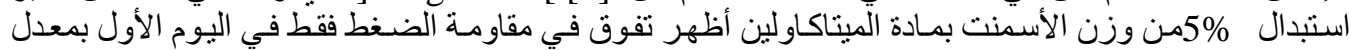

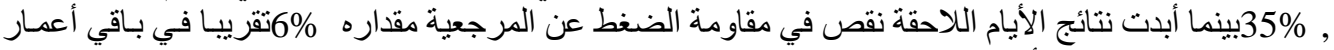

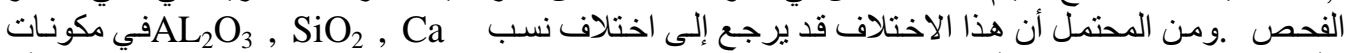

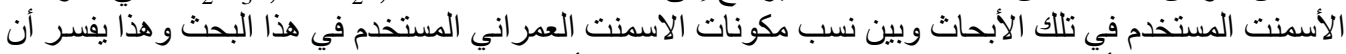

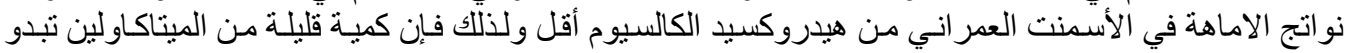

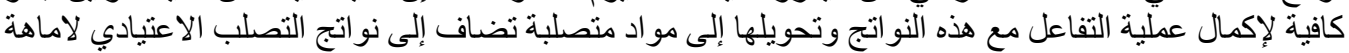

\section{2-1-3 الخرسانة مع استخدام المضاف الملان:(W/C=0.4 ) .}

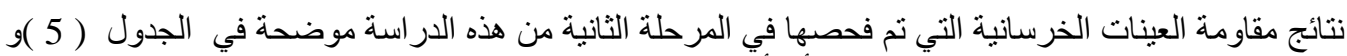

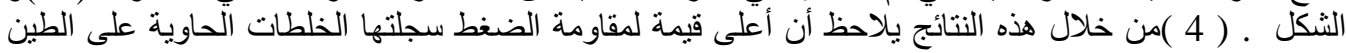

وبينت النتائج أيضا أن تأثير المضافات البوز لانية لا نظهر في المر احل الأولى من التصلب وكما حصل في نتائج

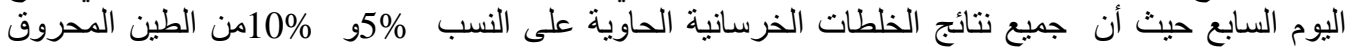

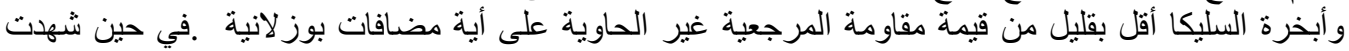

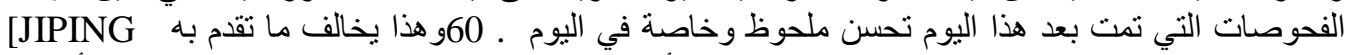

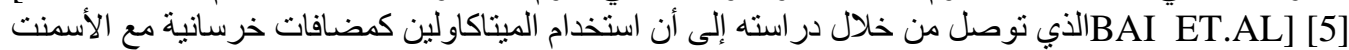

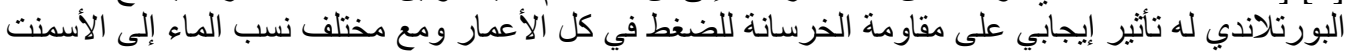


ولكن الارتفاع الأكبر لمقاومة الضغط سجلت في الأيام الأولى مع تراجع ملحوظ في ارتفاع مقاومة الضغط في المر احل الأخيرة للمعالجة الأليرة

الجدول 4 ) نتائج مقاومة ضغط الخلطات الخرسانية بدون استخدام الملان(W/C=0.55 )

\begin{tabular}{|c|c|c|c|c|c|c|c|c|c|}
\hline \multirow{2}{*}{$\begin{array}{l}\text { الكثافة } \\
\mathrm{kg} / \mathrm{m}^{3}\end{array}$} & \multirow{2}{*}{$\begin{array}{c}\text { الامتصاص } 28 \\
\text { عن العمر }\end{array}$} & \multicolumn{5}{|c|}{ مقاومة الانضغاط في العمر ( بالأيام ) } & \multirow{2}{*}{ المضأف } & \multirow{2}{*}{$\begin{array}{l}\mathrm{W} / \mathrm{C} \\
\%\end{array}$} & \multirow{2}{*}{ الخلطة } \\
\hline & & 60 & 28 & 14 & 7 & 3 & & & \\
\hline 2564 & 2.93 & 45.50 & 38.96 & 32.74 & 30.00 & 17.79 & \multirow{4}{*}{ مضافن } & 55 & Rf \\
\hline 2555 & 5.36 & 51.55 & 43.63 & 39.91 & 32.40 & 22.54 & & 55 & $\begin{array}{l}\text { MK } \\
\mathbf{5 \%}\end{array}$ \\
\hline 2510 & 2.99 & 34.88 & 32.48 & 25.57 & 20.60 & 12.57 & & 55 & $\begin{array}{l}\text { MK } \\
10 \%\end{array}$ \\
\hline 2508 & 5.72 & 39.20 & 39.75 & 36.66 & 25.53 & 17.12 & & 55 & $\begin{array}{l}\text { MK } \\
15 \%\end{array}$ \\
\hline
\end{tabular}

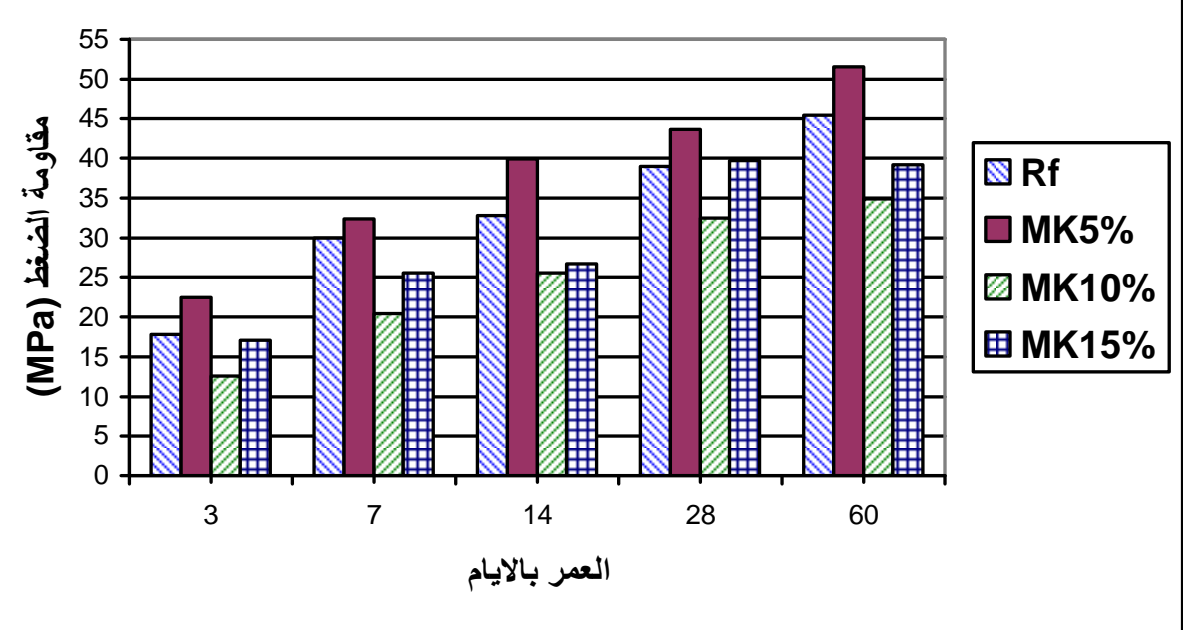

الشكل (3) مقاو مة ضغط عينات الحاوية على الطين المحروق و المرجعية.(W/C=0.55)

يلاحظ من الثكل 4 ) أن مقاومة ضغط الخلطات الحاوية على 5\%طين محروف في الأيام الأولى للتصلب ، أقل

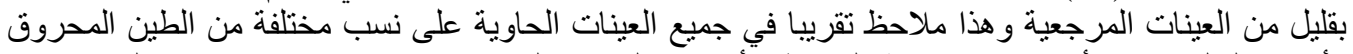

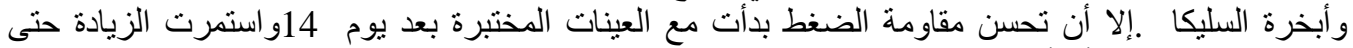

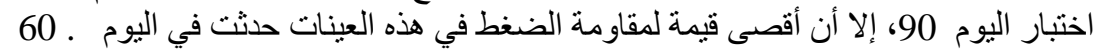

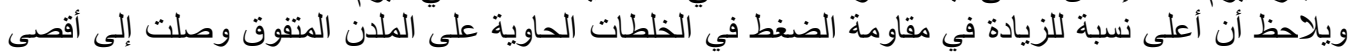
مقاومة في العينات الحاوية على إضافة 5\%طين محروق إلى إلى مكونات الخرسانة من بين العينات الخرسانية 
الحاوية على الملدن المتفوق ، وهذه النتيجة تؤكد نتائج العينات السابقة بدون استخدام المضاف الملدن التي بينت

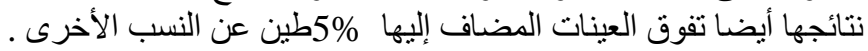

الجدول 5 ) نتائج مقاومة ضغط الخلطات الخرسانية باستخدام الملان المتفوق.(W/C=0.4 )

\begin{tabular}{|c|c|c|c|c|c|c|c|c|c|}
\hline \multirow{2}{*}{$\begin{array}{l}\text { الكثافة } \\
\mathrm{kg} / \mathrm{m}^{3}\end{array}$} & \multirow{2}{*}{ عند الامتصاص 28 عندر 28} & \multicolumn{5}{|c|}{ مقاومة الانضغاط في العمر ) بالأيـام } & \multirow{2}{*}{ المضاف } & \multirow[t]{2}{*}{$\begin{array}{c}\mathrm{W} / \mathrm{C} \\
\%\end{array}$} & \multirow{2}{*}{ رقم الخلطة } \\
\hline & & 90 & 60 & 28 & 14 & 7 & & & \\
\hline 2510 & 3.5 & 47.78 & 43.63 & 40.40 & 38.12 & 35.55 & \multirow{6}{*}{ لماستخدات } & 40 & $\begin{array}{c}\text { M1 } \\
\text { مرجعية }\end{array}$ \\
\hline 2556 & 3.5 & 54.76 & 52.03 & 47.83 & 45.08 & 34.42 & & 40 & $\begin{array}{c}\text { M2 } \\
\text { MK } 5 \%\end{array}$ \\
\hline 2534 & 3.45 & 48.88 & 50.58 & 45.14 & 41.37 & 34.74 & & 40 & $\begin{array}{c}\text { M3 } \\
\text { S.F5\% }\end{array}$ \\
\hline 2538 & 2.53 & 49.77 & 48.64 & 45.90 & 38.14 & 33.78 & & 40 & $\begin{array}{c}\text { M4 } \\
(\mathrm{MK}+ \\
\text { S.F }) 5 \%\end{array}$ \\
\hline 2513 & 2.57 & 48.00 & 51.71 & 42.39 & 38.95 & 34.75 & & 40 & $\begin{array}{c}\text { M5 } \\
\text { MK } 10 \%\end{array}$ \\
\hline 2513 & 2.72 & 49.77 & 49.45 & 42.17 & 39.91 & 34.32 & & 40 & $\begin{array}{c}\text { M6 } \\
\text { S.F10\% }\end{array}$ \\
\hline
\end{tabular}

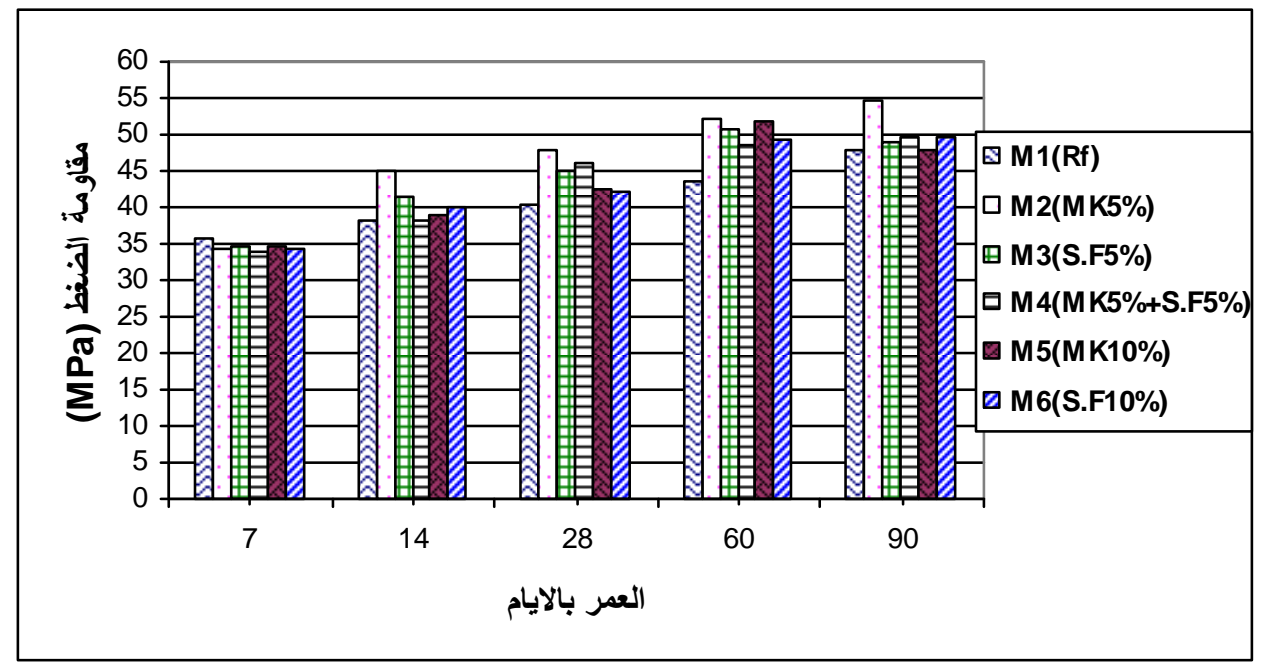

الثكل 4 ) مقاومة الضغط للعينات الحاوية على المضافات البوز لانية و المرجعية. (W/C=0.4 ) 


\section{2-3 مقاومة الثد ( Tensile Strength}

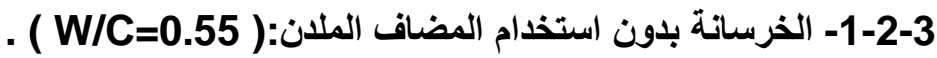

أظهرت العينات الحاوية على طين الكاولين المحروف تقدماً واضحاً في مقاومتها للثد بالمقارنة مع العينات

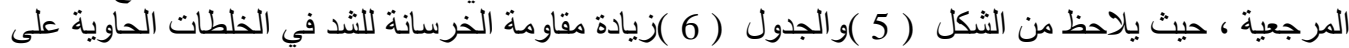

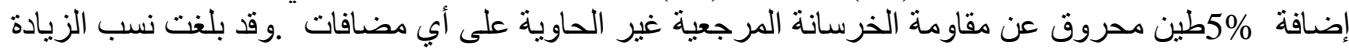

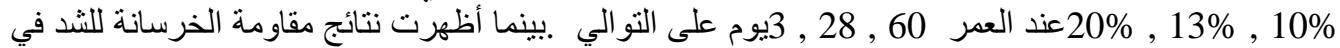

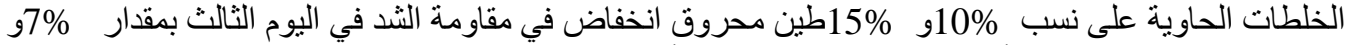

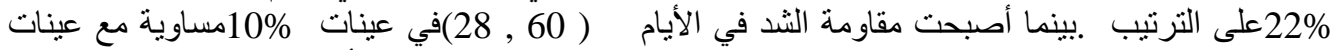

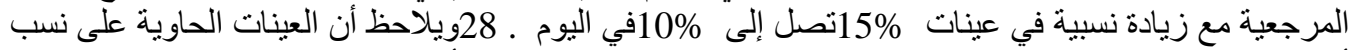

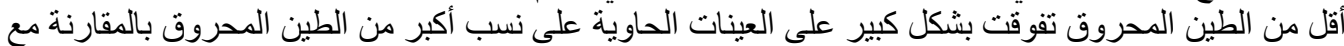

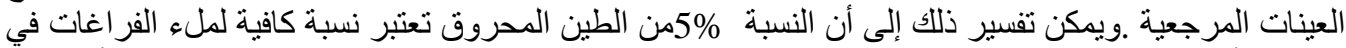

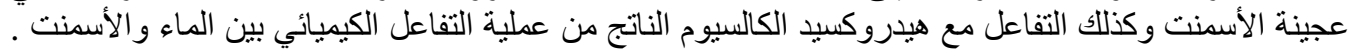

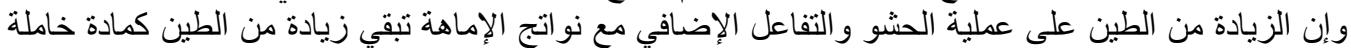

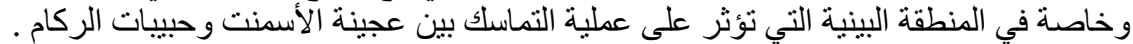

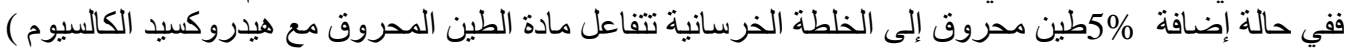

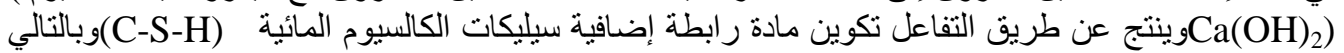

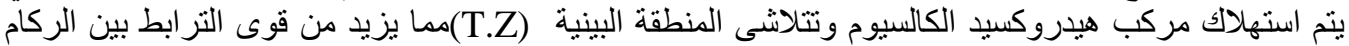

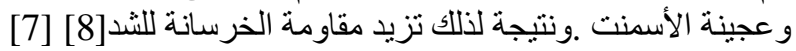

جدول ( 6 ) نتائج مقاومة العينات الخرسانية للشد بلون استخدام الملان.

\begin{tabular}{|c|c|c|c|c|c|c|}
\hline \multirow{2}{*}{$\begin{array}{l}\text { kg/m³ } \\
\text { kgثافة }\end{array}$} & \multicolumn{3}{|c|}{ مقاومة الانضغاط في العمر ( يوم ) } & \multirow{2}{*}{ المضاف } & \multirow{2}{*}{$\begin{array}{c}\mathrm{W} / \mathrm{C} \\
\%\end{array}$} & \multirow[t]{2}{*}{ رقم الخلطة } \\
\hline & 60 & 28 & 3 & & & \\
\hline 2463 & 3.47 & 3.43 & 1.70 & \multirow{4}{*}{ المضاف } & 55 & Rf \\
\hline 2471 & 3.92 & 3.89 & 2.06 & & 55 & MK5\% \\
\hline 2453 & 3.49 & 3.46 & 1.58 & & 55 & МК10\% \\
\hline 2435 & 3.63 & 3.77 & 1.32 & & 55 & MK15\% \\
\hline
\end{tabular}

\section{2-2-3-3 الخرسانة مع استخدام المضاف الملان(W/C=0.4 ) .}

من خلال نتائج فحص الاسطو انات الخرسانية لجميع الخلطات الخرسانية والمسجلة في الجدول ( 7 )يمكن

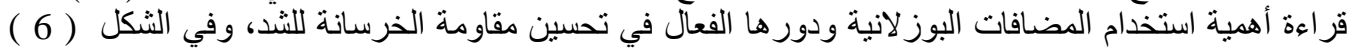

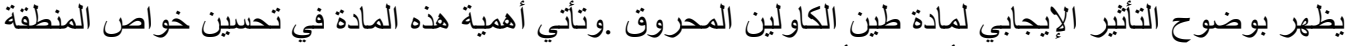

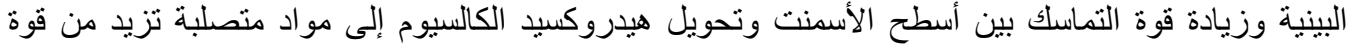

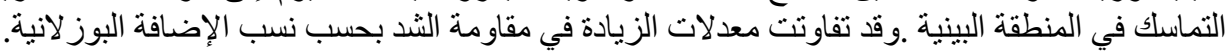

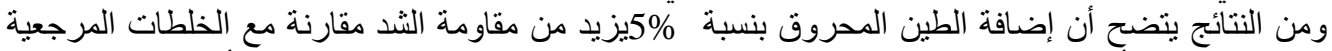

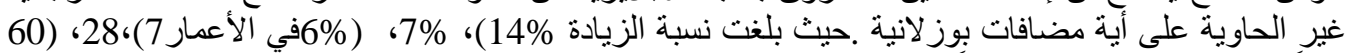

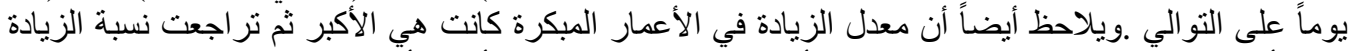

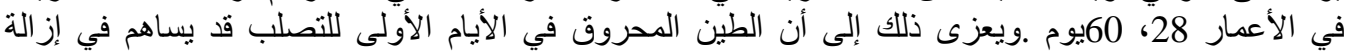


هيدروكسيد الكالسيوم الناتج من عمليات الإماهة الطبيعية، في حين أن كمية الطين المحروق غير كافية في الاستمرار في عملية الإماهة الإضافية في الأعمار المتأخرة .

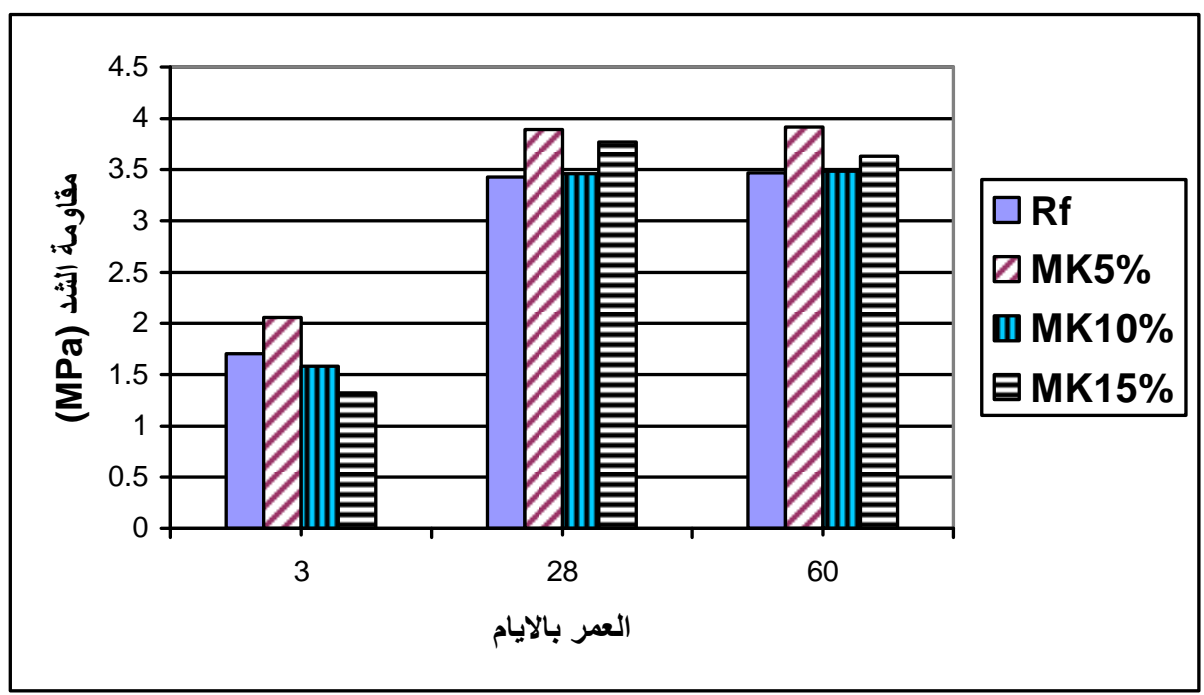

الثكل ( 5 ) مقاومة الثد في الخلطات المختلفة.(W/C=0.4)

بصورة عامة أظهرت العينات الحاوية على 10\% طين محروق ارتفاع متز ايد مع عمر العينات الحختبرة ووجد الحيد

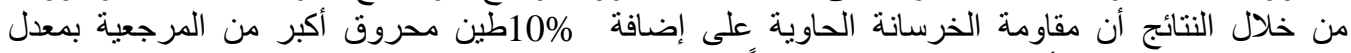

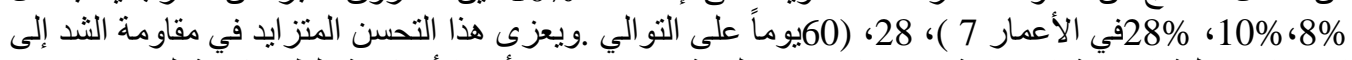

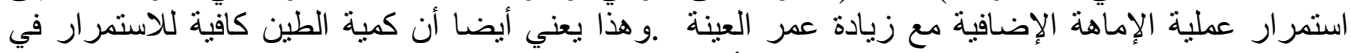

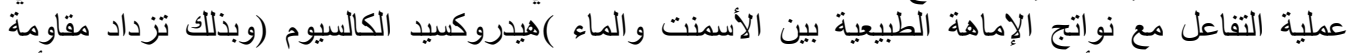

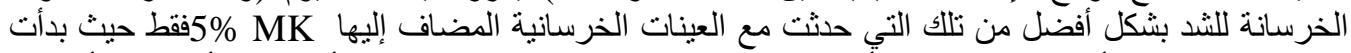

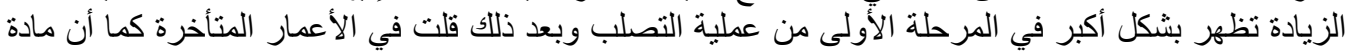

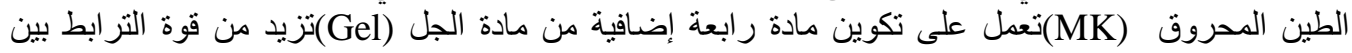

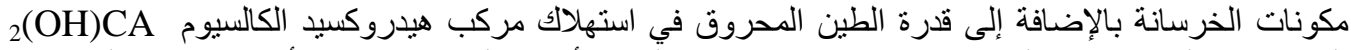

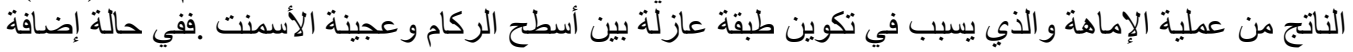

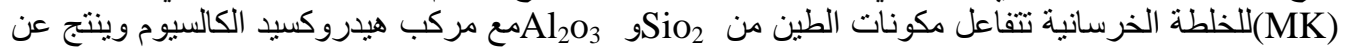

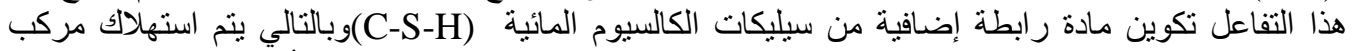

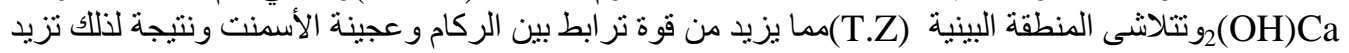
مقارنة الخرسانة للثد.

\section{3-3 تأثير الطين المحروق على متانة الخرسانة مع المضاف الملان(W/C=0.4 )} 3-3-3 1 تأثير إضافة الطين المحروق على امتصاص الخرسانة :

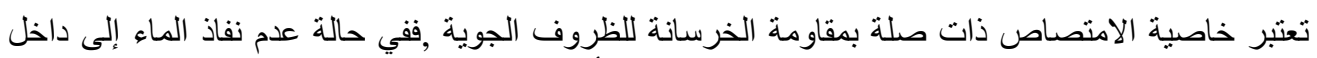

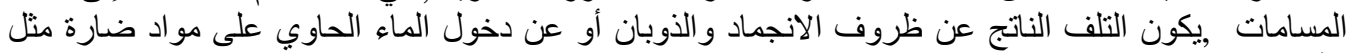

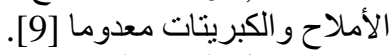

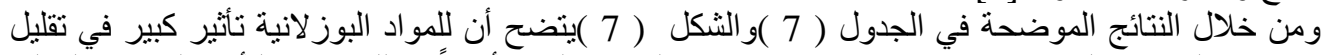

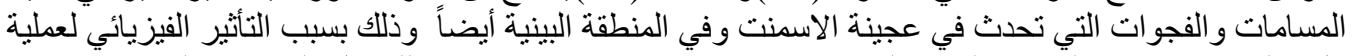

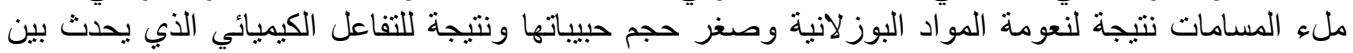


المواد البوزلانية المتمثلة بثاني أكسيد السيلكون

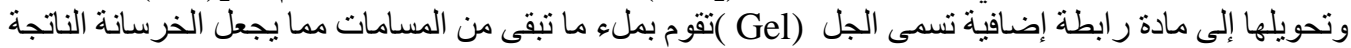

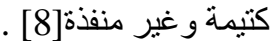

جدول ( 7) نتائج مقاومة العينات الخرسانية للثد باستخدام الملان.

\begin{tabular}{|c|c|c|c|c|c|c|}
\hline \multirow{2}{*}{ الكثافة } & \multicolumn{3}{|c|}{ مقاومة الانضغاط في العمر (بالأيام ) } & \multirow{2}{*}{ المضاف } & \multirow{2}{*}{$\begin{array}{l}\mathrm{W} / \mathrm{C} \\
\%\end{array}$} & \multirow[t]{2}{*}{ رقم الخططة } \\
\hline & 60 & 28 & 7 & & & \\
\hline 2481 & 4.57 & 4.30 & 3.46 & \multirow{6}{*}{ خلطات مع المتلان } & 40 & مرجعية \\
\hline 2491 & 4.70 & 4.62 & 3.96 & & 40 & $\begin{array}{c}\text { M2 } \\
\text { MK5\% }\end{array}$ \\
\hline 2496 & 4.76 & 4.72 & 3.68 & & 40 & $\begin{array}{c}\text { M3 } \\
\text { S.F5\% }\end{array}$ \\
\hline 2451 & 5.00 & 4.72 & 3.95 & & 40 & $\begin{array}{c}\mathrm{M} 4 \\
\mathrm{MK}+\mathrm{S} . \mathrm{F}) 5 \%)\end{array}$ \\
\hline 2484 & 5.70 & 4.72 & 3.75 & & 40 & $\begin{array}{c}\text { M5 } \\
\text { MK10\% } \\
\end{array}$ \\
\hline 2453 & 4.78 & 4.78 & 3.22 & & 40 & $\begin{array}{c}\text { M6 } \\
\text { S.F10\% }\end{array}$ \\
\hline
\end{tabular}
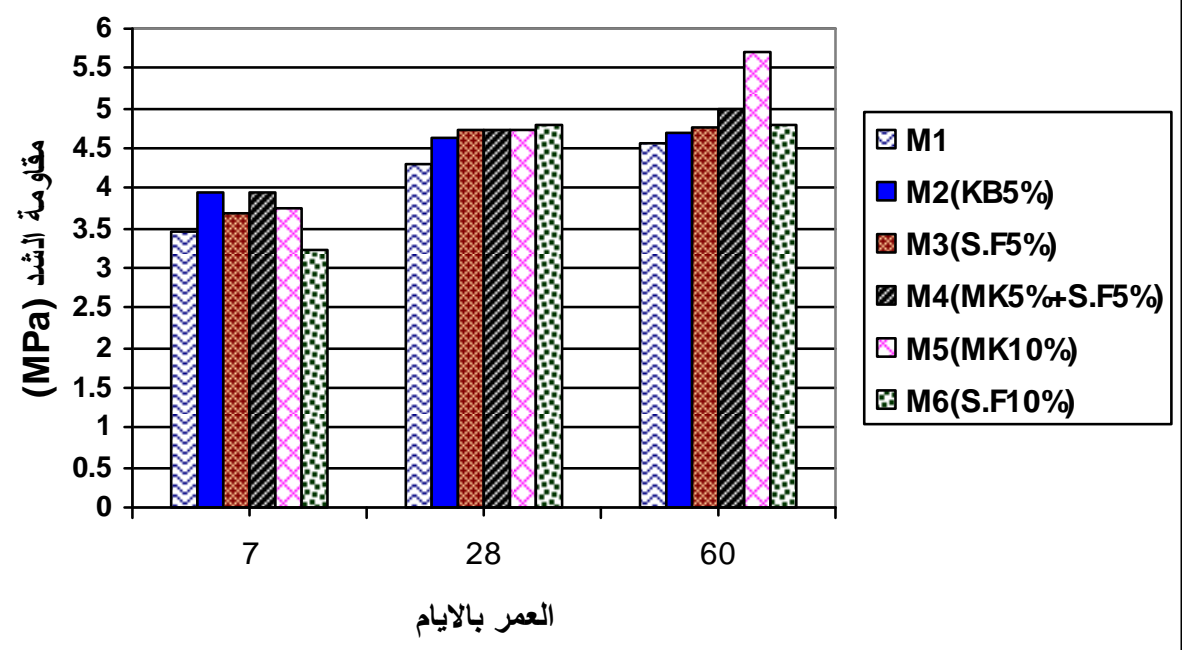

الثكل (6) نأثير نسب المضافات البوز لانية على مقاومة الخرسانة للثد..W/C=0.4 ) 
جدول ( 7 ) قيم امتصاص العينات الخرساتية

\begin{tabular}{|c|c|c|c|}
\hline الامتصاص عند العمر 28 & SP.\% & W/C & 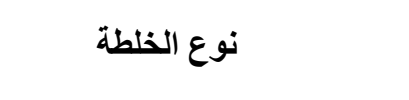 \\
\hline 3.50 & 4 & 0.4 & مرجعية \\
\hline 3.40 & 4 & 0.4 & حاوية على 5 \% \% \\
\hline 3.45 & 4.5 & 0.4 & حاوية على 5 S.F \% \\
\hline 2.53 & 4.5 & 0.4 & حاوية على S>F\% 5+MK\%5 \\
\hline 2.57 & 4.25 & 0.4 & حاوية على 10 10 ال \\
\hline 2.62 & 5 & 0.4 & S.F \% 10 حاوية على \\
\hline
\end{tabular}

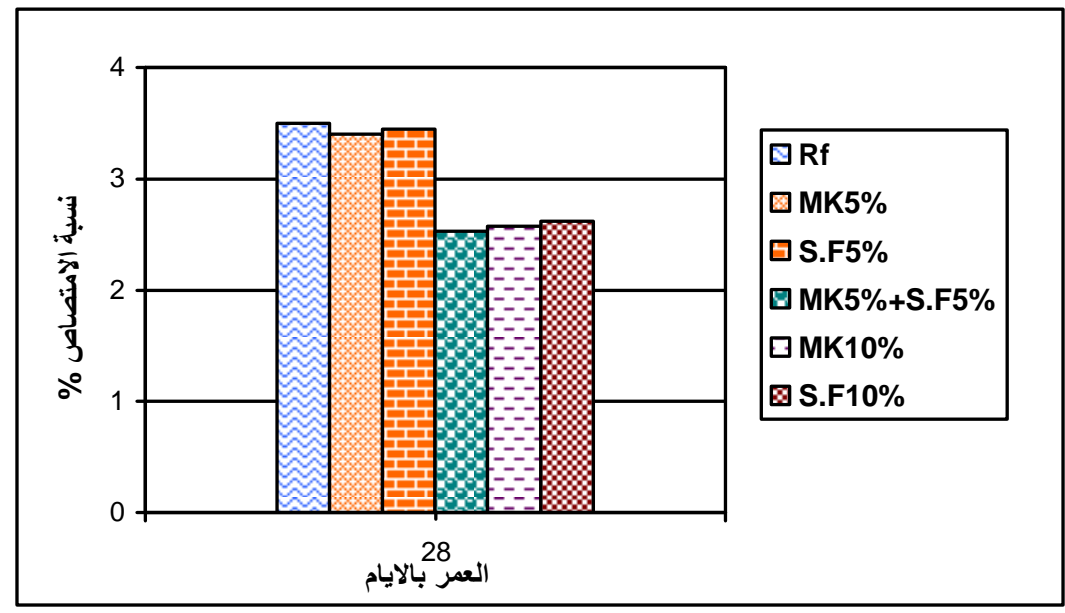

الثكل ( 7 ) تأثير الطين المحروق و أبخرة السيليكا على امتصاص الخرسانة.

إن تأثير إضافة 5من الطين المحروق إلى مكونات الخرسانة أبدت تأثير طفيف في تغير خاصية الامتصاص

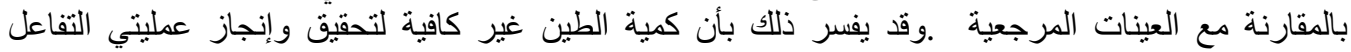

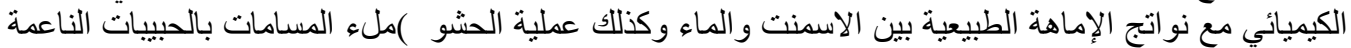

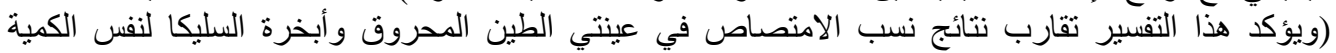
المضافة .

يتضح من النتائج الموضحة في الجدول ( 7 )والثكل ( 7 ) أن الطين المحروق يلعب دور فعال في إقفال

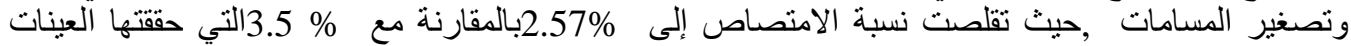

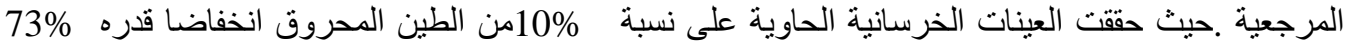

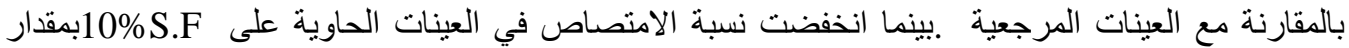

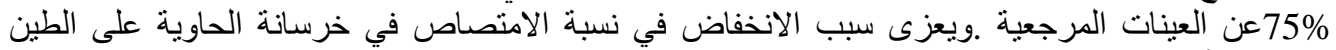

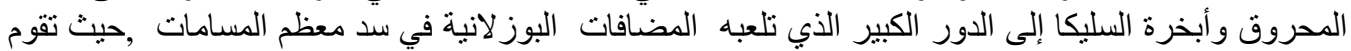

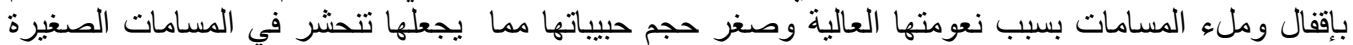

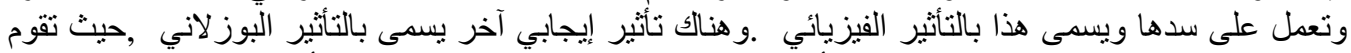

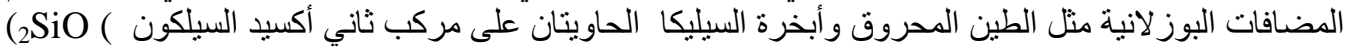
بالتفاعل مع مركب هيدروكسيد الكالسيوم الكالسيوم (C-S-H) تقوم هذه المادة بملء ما تبقى من مسافات بمادة متصلبة مما يجعل الخرسانة الناتجة عالية 
مع الكثافة وكتيمه و غير منفذة ـ [8] عند مقارنة الخرسانة الحاوية على المضافات البوزلانية (MIC) , (S.F)

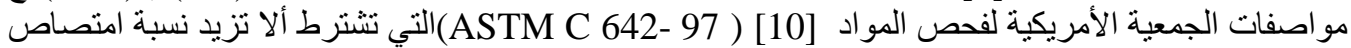

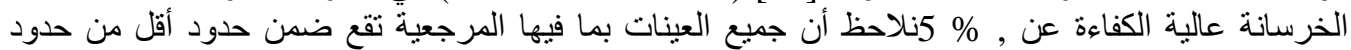

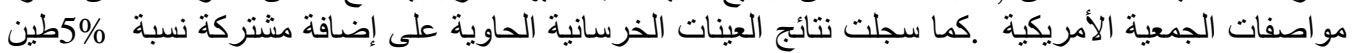
محروق و 5\%أبخرة السيليكا أقل نسبة امتصاص مقدات مقار ها

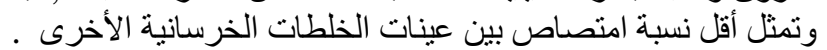

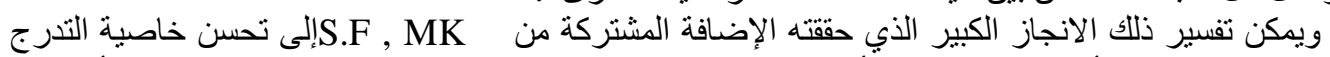

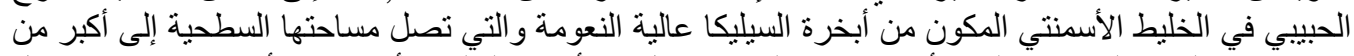

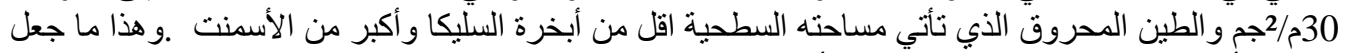

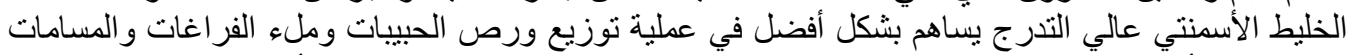

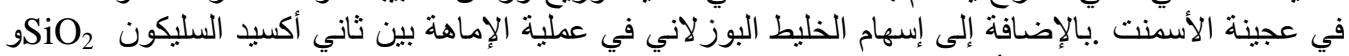
نواتج الإماهة الطبيعية بين الأسمنت و الماء. الإمئ.

\section{2-3-3 - 2-أثير إضافة الطين المحروق على نفاذية الخرسانة :}

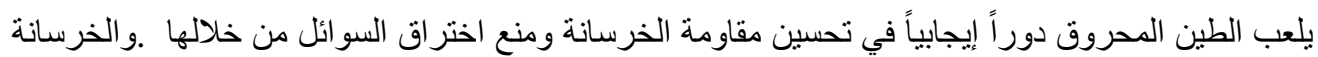

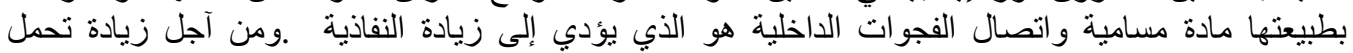

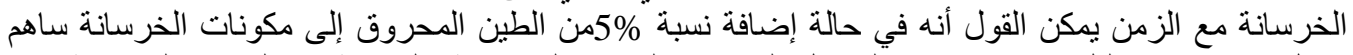

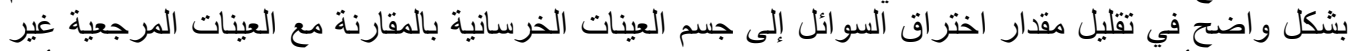

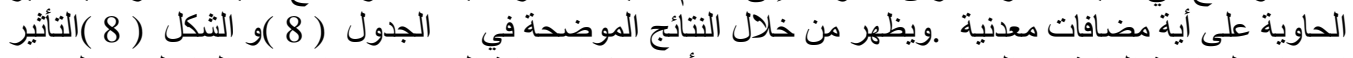

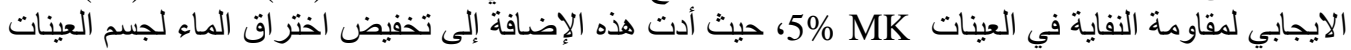

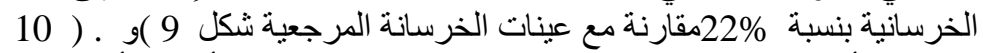

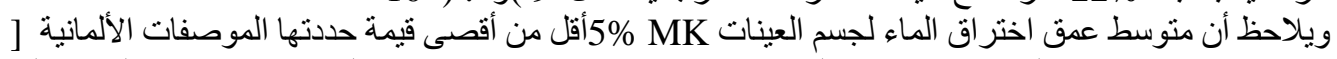

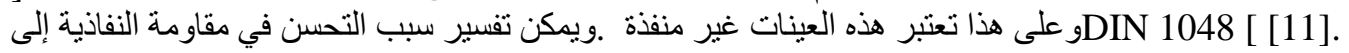

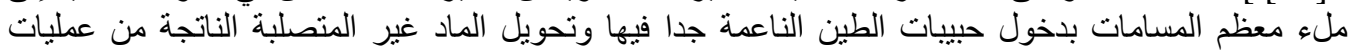

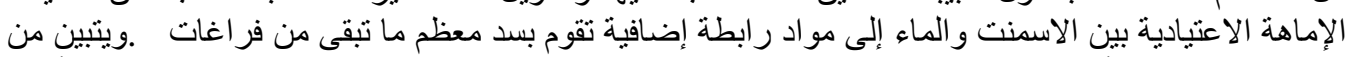

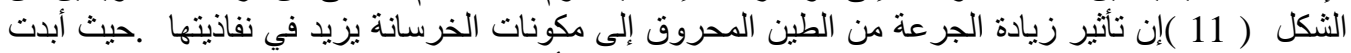

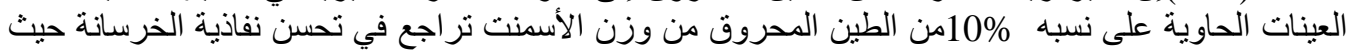

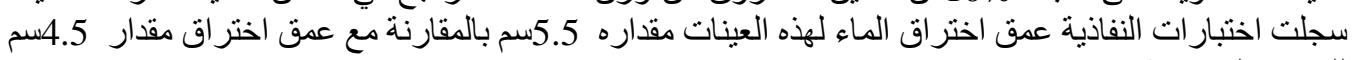

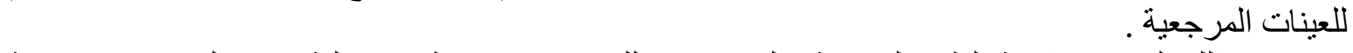
وقد يفسر ذللك إلى زيادة كمية الطين المضافة والتي قد يستنهلك جزء منها فقط في عملية إملاء المسافات و الإماهة

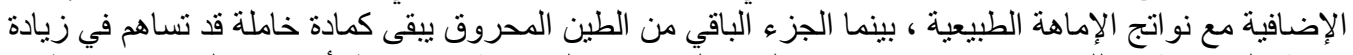

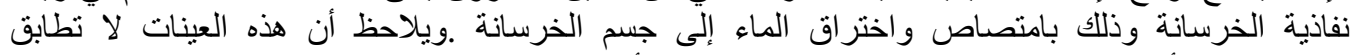

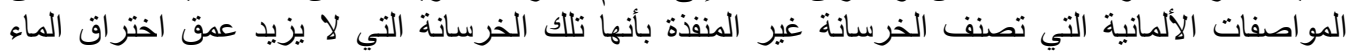

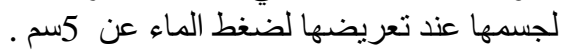

جدول ( 8 ) مقدار الاختراق في العينات الخرساتية .

\begin{tabular}{|c|c|c|c|}
\hline 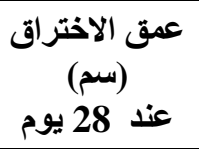 & 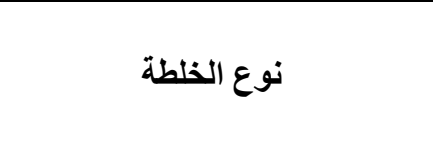 & 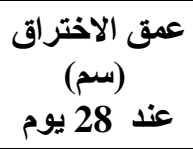 & 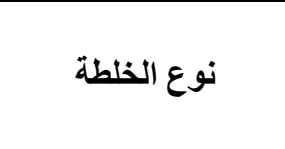 \\
\hline 6 & حاوية على 5.F MK+5\% S.F & 4.5 & مرجعية \\
\hline 5.5 & 10\% MK حاوية على & 3.5 & حاوية على MK \\
\hline 3.5 & 10\% S.F حاوية على & 6 & حاوية على S.F S \\
\hline
\end{tabular}




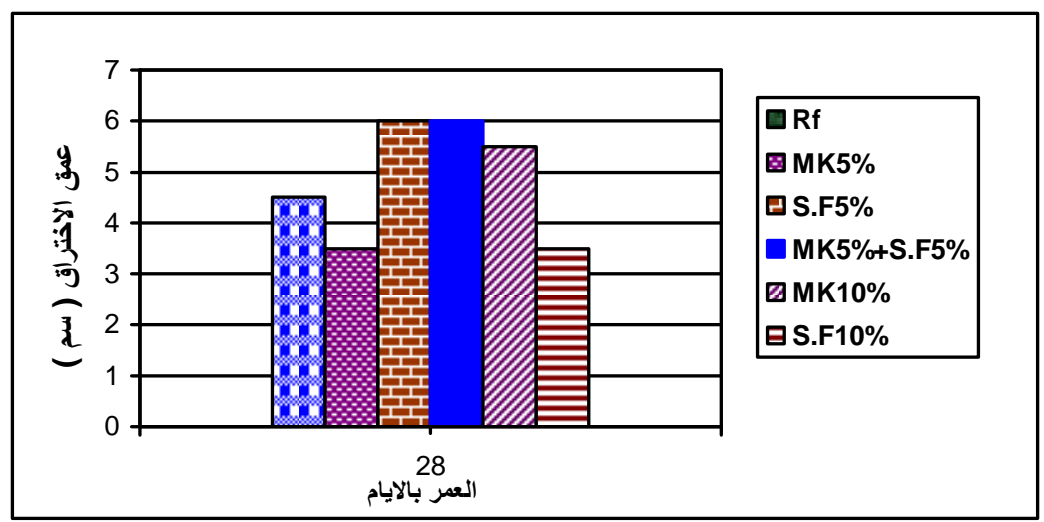

الثكل ( 8 ) نأثثر نوع ونسبة الإضافة على نفاذية الخرسانة

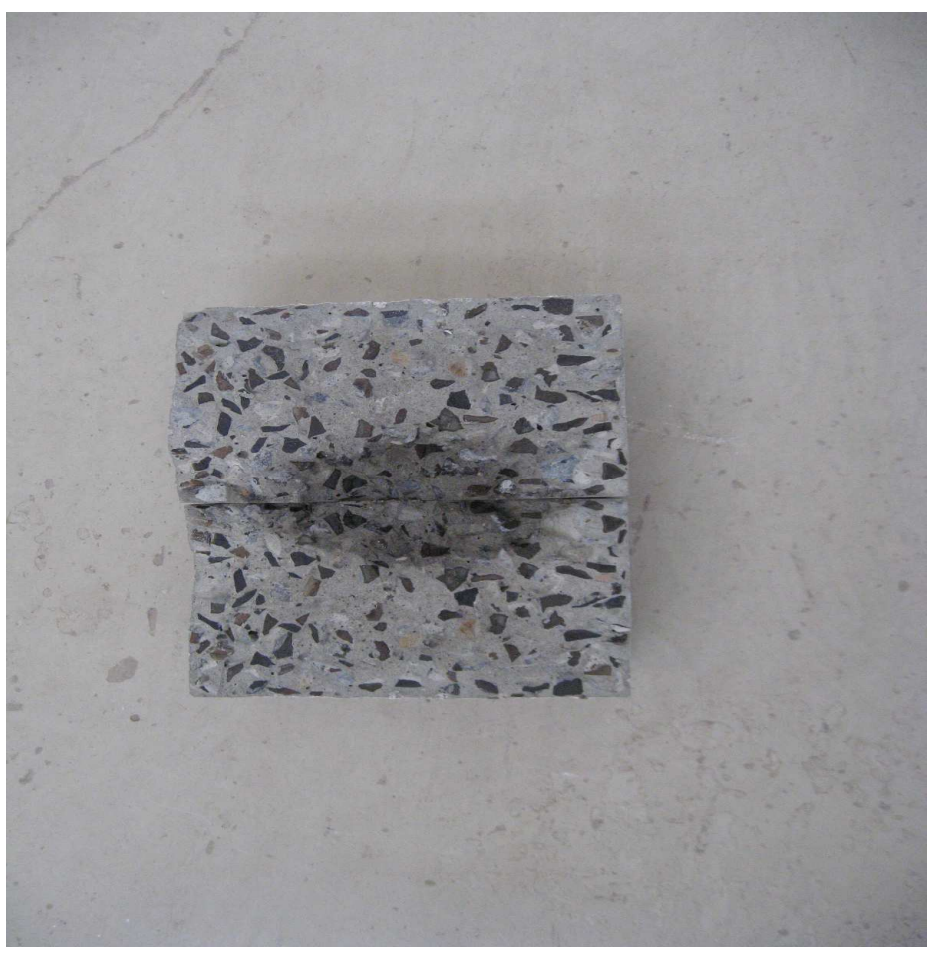

الثكل ( 9 ) مقدار عمق اختراق الماء في

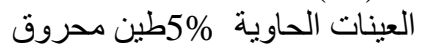




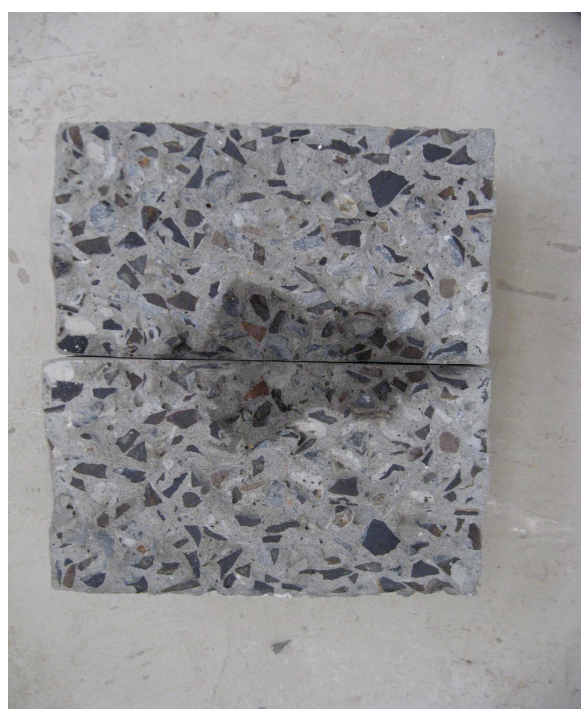

$$
\text { الثكل ( } 10 \text { الماء في العينات المرجعية. اختراق }
$$

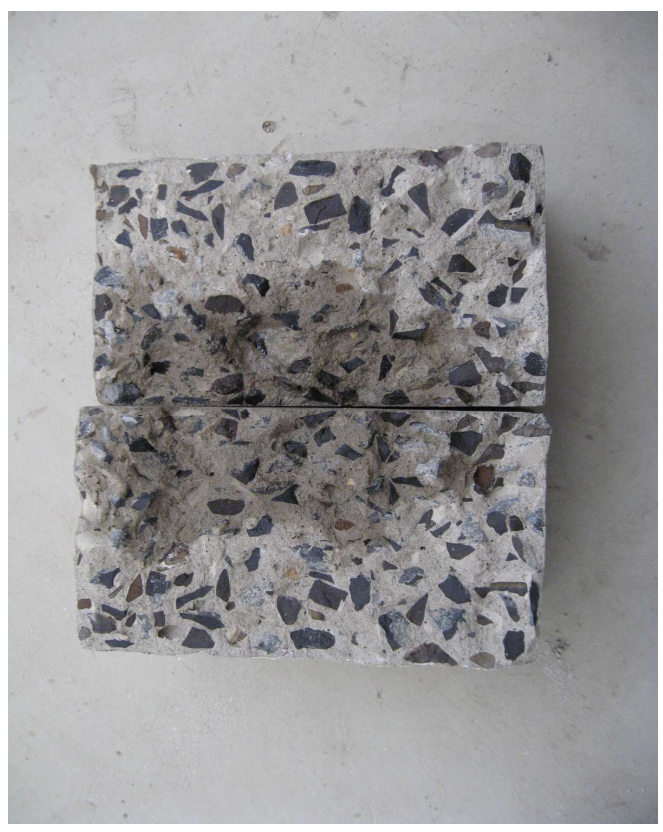

$$
\text { الشكل الحاوية 10\% 10\% اخين محروق الماء في العينات }
$$




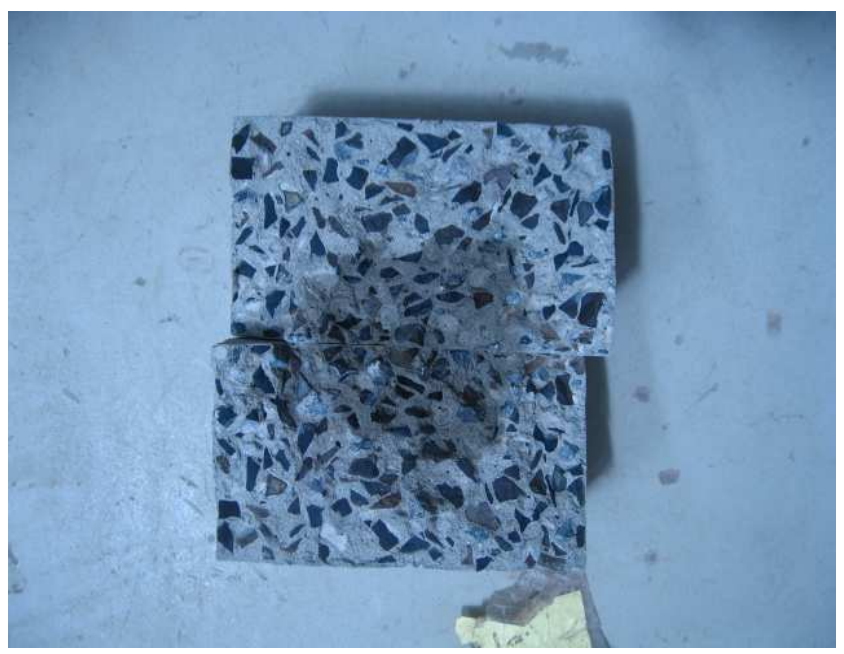

الثكل ( 12)مقدار عمق اختراق الماء في

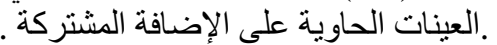

4

أوضحت النتائج أن إضافة طين الكاولين المحروق إلى مكونات الخرسانة له نأثيراً إيجابياً على مقاومة

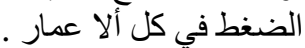

يختلف تأثثِر طين الكاولين المحروق على مقاومة الخرسانة للضغط بحسب نسبة الإضافة ، حيث سجلت

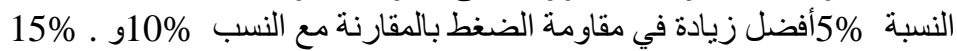

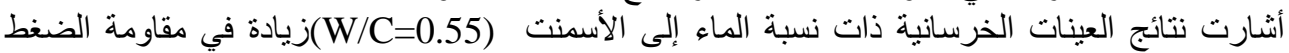

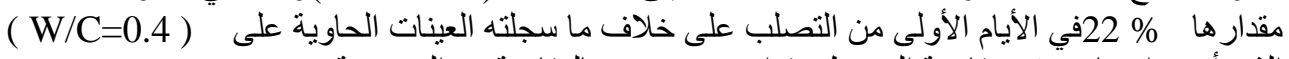

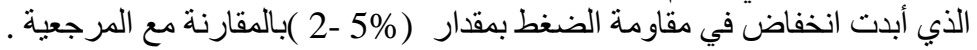

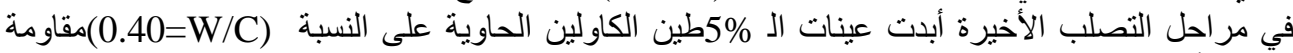

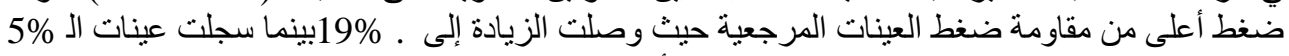

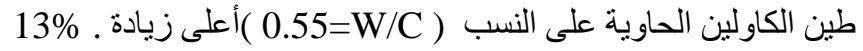

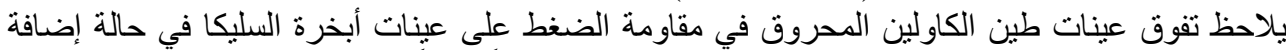

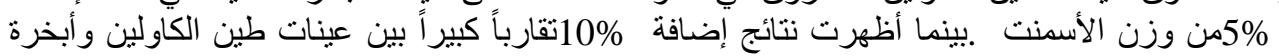

السليكا.

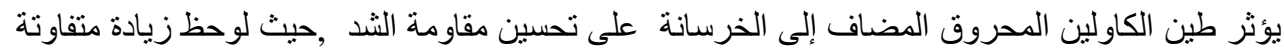

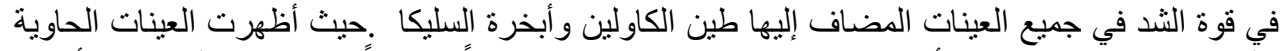

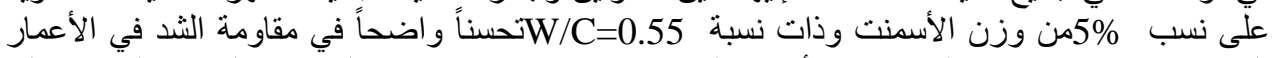

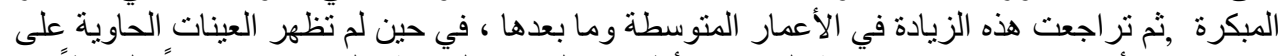

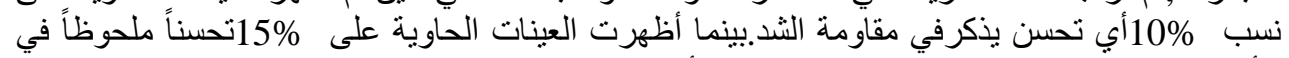
الأعمار فوق 28يوم وذلك بالمقارنة مع عينات الأسطو انات المبات المرجعية.

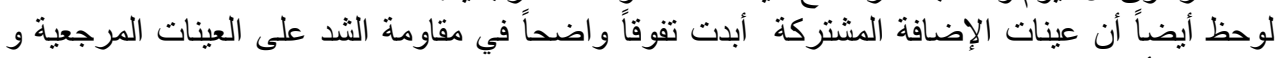

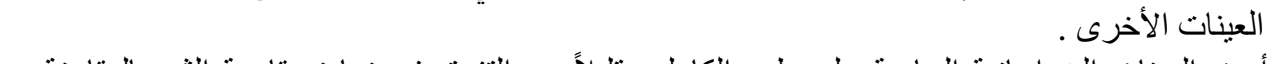
أبدت العينات الخراسانية الحاوية على طين الكاولين قليلاً من التفوق في زيادة مقاومة الثد بالمقارنة مع

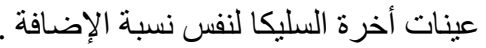

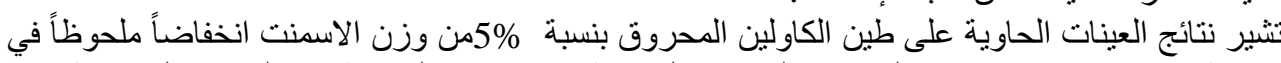

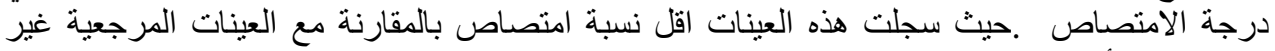
الحاوية على أية مضافات بوز لانية . 


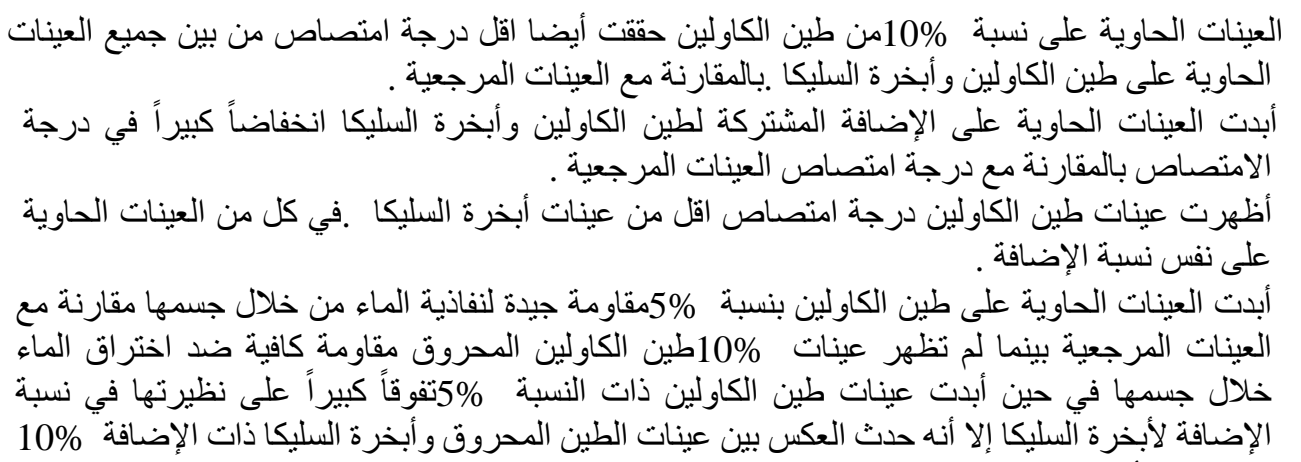

\section{REFERENCES}

1- Neville A., and Aitcin, P.-C., "Hight performance Concrete- An overview “, Materials and Structures, 31, 111-117 (1998)

2- J. Ninov, I. Donchev, A. Lenchev, I. Granchavov, “ Chemical Stabilization of Sand Iillite Clay "Faculty of Chemistry 1 James Bouchier , 1126 Sofia , Bulgaria . 2003.

3- Karsten Mitlrath, “ Modifying Concrete Matrices With Beneficiated Dredged Material or Other Clayey Constituents " a thesis submitted in partial fulfillment of the requirements for the degree of doctor of philosophy, Columbia University , 2003.

4- Amer Bin Yusuff, "Behavior of high Strength Reinforced Concrete Beam_with Metakaolin under Static Loading “ Project Report submitted in partial fulfillment of the requirements for the degree of master of engineering . Faculty of civil engineering, University Teknologi Malaysia April 2005

5- Jiping Bai , Stan Wild, Albinas Gailius, "Accelerating Early Strength Development of Concrete Using Metakaolin as an Admixture " School at Technology University of Glamorgan , Pontypridd , CF 37 1DL , United Kingdom . sep. 2004

6- Ong chee huat. "performance of concrete containging metakaolin as cement replacement material" aproject report submitted in partial fulfillment of the requirements for the award of the degree of master of engineering structures. Faculty of civil engineering university technology maleysia nov.2006.

7- David Trejo and Ceki Halmen , "Evaluation of Thiele Metakaolin for applications in Concrete "Department of civil engineering. Texas A\&M University .August, 2006 .

8- Salih, S. A., “ Permeability and pore Structure of Cementitous Composites “ Ph. D. Thesis, University of Sheffield .1987

9- A. Darweesh, “Concrete Mixture “, Faculty of Engineering, University of Asuot .

10- "Standard Test Method for Density, Absorption and Voids in Hardened Concrete ", ASTM C 642-97

11- Deutsches Institute fur Normung, DIN 1048, “ Test Method for Concrete “ December 1978. 